
\title{
CARTILHA EDUCATIVA PARA ORIENTAC̃̃O MATERNA SOBRE OS
CUIDADOS COM O BEBE PREMATURO
}

Luciana Mara Monti Fonseca ${ }^{2}$ Carmen Gracinda Silvan Scochi Semiramis Melani Melo Rocha ${ }^{3}$ Adriana Moraes Leite

Fonseca LMM, Scochi CGS, Rocha SMM, Leite AM. Cartilha educativa para orientação materna sobre os cuidados com o bebê prematuro. Rev Latino-am Enfermagem 2004 janeiro-fevereiro; 12(1):65-75.

O objetivo do presente estudo foi descrever o desenvolvimento de material didático-instrucional, dirigido ao treinamento materno para preparar a alta hospitalar do bebê prematuro, utilizando metodologia participativa. O modelo pedagógico utilizado foi a educação conscientizadora, fundamentada em Paulo Freire. Participaram do estudo 2 enfermeiras, 2 auxiliares de enfermagem e 4 mães de bebês prematuros internados na unidade de cuidados intermediários de um hospital universitário de Ribeirão Preto, SP. Os participantes indicaram os assuntos de interesse para o processo ensino-aprendizagem, os quais foram agrupados em cuidados diários, alimentação, higiene, cuidados especiais e relacionamento familiar. Decidiram pela confecção de uma cartilha educativa ilustrada com figuras, que pudesse ser levada para o domicílio. A confecção desse material didático-instrucional foi feita pelas pesquisadoras tendo por base a literatura, experiência profissional e assessoria técnico-científica de outros profissionais. A versão final da cartilha educativa foi validada pelos participantes e constitui instrumento criativo para auxiliar nas atividades de educação em saúde dirigida a essa clientela. Para os participantes, o material educativo direcionou as orientações e auxiliou as mães na memorização dos conteúdos a serem apreendidos.

DESCRITORES: prestação de cuidados de saúde; educação em saúde; instrução programada; prematuro; enfermagem

\section{EDUCATIONAL GUIDELINE FOR THE MATERNAL ORIENTATION CONCERNING THE CARE WITH PRETERM INFANTS}

This work aimed at describing the development of educational and instructional material for maternal training, so as to prepare the mother for the preterm infants' discharge from hospital, by means of the participatory methodology. The pedagogical model used was that of education for critical consciousness, based on Paulo Freire. Study participants were two nurses, two nursing auxiliaries and four mothers of preterm babies, which were hospitalized at the Intermediate Care Unit of a university hospital in Ribeirão Preto-SP, Brazil. The participants indicated the subjects of interest for the teaching-learning process, which were grouped into the categories: daily care, feeding, hygiene, special care and family relationship. We decided to develop an educational folder with figures, which could be taken home. This educational and instructional material was produced by the researchers on the basis of literature, their professional experience and on technical and scientific advice from other professionals. The final version of the folder was validated by the participants and now constitutes a creative instrument that can be of help in health education activities oriented towards these clients. According to the participants, the educational material directed the guidelines and helped the mothers to memorize the content that had to be learned.

DESCRIPTORS: health care delivery; health education; programmed instruction; infant, premature; nursing

\section{FOLLETO EDUCATIVO PARA ORIENTACIÓN MATERNA SOBRE LOS} CUIDADOS CON EL BEBE PREMATURO

El objetivo del presente estudio fue describir el desarrollo de material didáctico-instructivo dirigido al entrenamiento materno para preparar la alta hospitalaria del bebe prematuro, utilizando la investigación participativa. El modelo pedagógico utilizado fue la educación concientizadora, fundamentada en Paulo Freire. Participaron del estudio 2 enfermeras, 2 auxiliares de enfermería y 4 madres de bebes prematuros hospitalizados en la Unidad de Cuidados Intermediarios de un Hospital Universitario de la ciudad de Ribeirão Preto-SP. Los participantes indicaron los asuntos de interés para el proceso enseñanzaaprendizaje, los cuales fueron agrupados en cuidados diarios, alimentación, higiene, cuidados especiales y relación familiar; decidieron por la confección de un folleto educativo ilustrado con figuras, para ser llevado al domicilio. La confección de ese material didáctico fue realizada por las investigadoras, basadas en la literatura, experiencia profesional y asesoría técnicocientífica de otros profesionales. La versión final del folleto educativo fue validada por los participantes y constituye un instrumento creativo para ayudar en las actividades de educación en salud dirigida a esta clientela. Para los participantes, el material educativo ha orientado y ayudado a las madres en la memorización de los contenidos a ser aprehendidos.

DESCRIPTORES: prestación de atención de salud; educación en salud; instrucción programada; prematuro; enfermería

\footnotetext{
${ }^{1}$ Resumo da Dissertação de Mestrado defendida em 1o de março de 2002, Escola de Enfermagem de Ribeirão Preto, da Universidade de São Paulo; ${ }^{2}$ Enfermeira, Mestre pelo Programa de Pós-Graduação Enfermagem em Saúde Pública, e-mail: lumonti@eerp.usp.br; ${ }^{3}$ Professoras, email: cscochi@eerp.usp.br. Escola de Enfermagem de Ribeirão Preto, da Universidade de São Paulo, Centro Colaborador da OMS para o desenvolvimento da pesquisa em enfermagem
} 
INTRODUÇÃO

Em um diagnóstico das práticas de educação em saúde, realizado pelo Ministério da Saúde, a partir de documentos governamentais disponíveis, são apontadas as seguintes características: verticalidade, descontinuidade, predominância da fundamentação biológica, desarticulação de saberes, não participação, enfoque mecanicista e ausência de unidade conceitual ${ }^{(1)}$. Depreende-se que a atuação em saúde com essas características não é passível de gerar transformações e, portanto, não proporciona mudanças na qualidade de vida.

O momento exige um novo pensar a Educação e a Saúde, não mais como educação sanitarizada (educação sanitária) ou localizada no interior da saúde (educação em saúde), ou ainda educação para a saúde (como se a saúde pudesse ser um estado em que se atingisse depois de educado!). É preciso recuperar a dimensão da Educação e da Saúde/Doença e estabelecer as articulações entre esses dois movimentos (organizados e não organizados) sociais ${ }^{(2)}$.

Novo enfoque vem sendo proposto pela área da Educação em Saúde, em uma linha de planejamento participativo, a Educação para a Participação em Saúde, que objetiva suscitar o envolvimento da população em geral nos programas de saúde, promover transformações conceituais na compreensão da saúde, relacionando-a à qualidade e compromisso com a vida e não, simplesmente, à ausência de enfermidades e gerar atitudes e procedimentos novos frente aos problemas da doença, de modo que a saúde seja encarada como responsabilidade de todos e não somente atribuição governamental ${ }^{(3)}$.

A Educação para a Participação em Saúde concebe o homem como sujeito principal, responsável por sua realidade; suas necessidades de saúde são solucionadas a partir de uma ação consciente e participante. Sob essa perspectiva, a Educação em Saúde deve comprometer-se a assistir uma clientela de crescente complexidade, como a dos bebês pré-termo e suas famílias. Temos particular interesse nesse grupo pela sua alta demanda por serviços de saúde e necessidades de cuidados, caracterizados como problemas de saúde pública, no Brasil e em diversos países.

A assistência à saúde dos bebês pré-termo passou por grandes transformações através dos tempos. Foi centrada na recuperação do corpo anátomo-fisiológico, tendo como finalidade a redução da mortalidade. Depois, transformou-se em assistência mais integral e humanizada com ênfase no processo saúde-doença, tendo como objetivo o crescimento e desenvolvimento da criança e a qualidade de vida ${ }^{(4)}$.

Se antes a mãe era excluída da assistência em berçário de risco, agora ela passa a ser também sujeito, uma aliada, no processo de assistência, sendo permitida sua maior permanência junto ao filho prematuro e participação no cuidado dele. À medida que a família vai sendo inserida no espaço das unidades neonatais, ela traz consigo suas necessidades no processo de vivenciar o nascimento prematuro, os sentimentos de ter um filho com riscos de danos e morte, as dificuldades de ter que assumir o cuidado cotidiano de um filho que necessitará de cuidados especiais a longo prazo, além dos aspectos relacionados às condições socioculturais ${ }^{(4)}$.

O treinamento da mãe para o cuidado domiciliar do bebê se dá durante toda a internação do prematuro, procurando-se desenvolver habilidades e transmitir conhecimentos específicos.

A literatura tem enfatizado a importância do preparo das mães para a alta hospitalar durante toda a hospitalização do bebê, reduzindo a ansiedade e aumentando a autoconfiança materna no cuidado domiciliar. Dessa forma, a adaptação da família à criança, após a alta hospitalar, é facilitada ${ }^{(5-6)}$.

Cabe ao enfermeiro o preparo para a alta, por estar mais próximo da criança e da família e possuir visão mais ampla das necessidades de saúde da criança ${ }^{(7)}$.

Encontramos na literatura um plano pedagógico onde há duas listas de tópicos que devem ser lembrados no ensino de pais de bebês com algum risco, uma geral e outra específica. Os tópicos pedagógicos gerais incluem: cuidados físicos, segurança infantil envolvendo supervisão adequada, ressuscitação cardiopulmonar, acompanhamento do desenvolvimento, estado de saúde atual e indicadores de problemas, seguimento, informações acerca da paternidade/maternidade; números de telefones importantes como aqueles pertinentes à assistência primária, UTIN, emergência local, entre outros. Nos tópicos pedagógicos específicos constam: processo doença/seqüela, habilidades na avaliação física envolvendo sinais vitais, mudança de apetite e de comportamento, administração de medicamentos, tratamentos e procedimentos como fisioterapia respiratória, sucção, oxigenioterapia, cuidados com a traqueostomia, terapia de inalação, mecanismo ventilatório, cuidados com a 
colostomia, gavagem, alimentação por gastrostomia, uso e manutenção de equipamentos, segurança relativa ao uso de oxigênio, monitores, traqueostomia, armazenamento de medicações, seguimento envolvendo a avaliação do desenvolvimento, orientação antecipatória sobre as necessidades emocionais e sociais da família, reospitalizações, alternativas de cuidado domiciliar ${ }^{(8)}$.

Foram encontrados poucos estudos sobre as necessidades de aprendizagem de pais de prematuros, embora alguns autores fizessem alusão a elas.

Há um estudo que examinou os projetos destinados às mães de prematuros ou de crianças nascidas de baixo peso, tendo como objetivos identificar e descrever características específicas de cada projeto de aprendizagem, relacionado ao nascimento e ao cuidado dessas crianças. Os tópicos dos 193 projetos de aprendizagem encontrados foram agrupados pela autora em 10 categorias: desenvolvimento infantil, mudanças no estilo de vida, cuidado hospitalar da criança, aprendendo sobre si própria, convivendo com a criança prematura em casa, cuidados básicos com a criança, alimentação infantil, relações familiares, saúde da criança e nascimento cesareano $^{(9)}$.

Os recursos de aprendizagem foram categorizados como: profissional (em primeiro lugar aparecem as enfermeiras, depois doutores e nutricionistas) e não-profissional (amigos, marido, parentes), impressos (livros, jornais, folhetos e revistas), outros (filmes, televisão, o quadro de crianças hospitalizadas). A maioria das mães indicou algum tipo de obstáculo ao aprendizado que a autora categorizou como internos (ansiedade, medo, insegurança, raiva, frustração e culpa) e externos (respostas insatisfatórias de profissionais, falta de alguém para conversar sobre o problema, inacessibilidade aos recursos impressos apropriados). Outros obstáculos incluíram recomendações incompatíveis relativas à alimentação da criança. As mães identificaram como tópicos mais importantes do aprendizado o autoconhecimento, mudança de estilo de vida, cuidados com a criança e desenvolvimento infantil. Algumas mães expressaram dificuldade em entender a terminologia médica ${ }^{(9)}$.

Através de nossa inserção na unidade neonatal, percebemos a escassez de materiais didáticoinstrucionais para auxiliar na orientação de mães, preparando-as para a alta hospitalar de seus filhos. Os treinamentos eram individuais, normativos, não havendo troca de experiências ou técnicas criativas.

Sabemos das dificuldades e escassez de recursos físicos, humanos, estruturais e materiais em grande parcela dos serviços de saúde. Essa carência põe em risco a prática educativa, tornando-a monótona, desestimulante e repetitiva, para o profissional e para a clientela. Por outro lado, não é possível ficarmos imobilizados até que mudanças macroestruturais e sociais ocorram. Na prática cotidiana, em berçário de prematuros, há espaço para o desenvolvimento de atividades educativas, visando a melhoria da qualidade da assistência de enfermagem.

Preocupados com as estratégias e instrumentos passíveis de uso nas atividades de Educação em Saúde, dirigidas às puérperas, em alojamento conjunto neonatal, elaboramos um jogo educativo contendo perguntas e respostas sobre os cuidados básicos com o recémnascido a termo e a amamentação materna ${ }^{(10)}$. Posteriormente, realizamos estudo analisando o uso desse jogo, na perspectiva materna. Ele foi considerado pelas mães uma estratégia divertida e estimulante, deixandoas mais atentas, soltas, abertas a aprender e a ensinar. Essa experiência oportunizou desenvolver a atividade de Educação em Saúde utilizando recursos não usuais dessa prática, estimulando a participação efetiva tanto das puérperas como dos profissionais de saúde ${ }^{(11)}$.

Acreditamos que os materiais didáticos dinamizam as atividades de Educação em Saúde, o que nos estimula a construí-los.

A educação democrática se funda na crença de que o homem deve discutir os problemas e analisar a realidade do seu trabalho, do seu mundo, do seu país e do seu continente. Foi proposto um modelo de educação capaz de contribuir para a inserção do homem na sua realidade, baseado num método ativo, dialogal, crítico, problematizador e participante, utilizando o diálogo, como relação horizontal entre dois pólos ${ }^{(12)}$.

A educação problematizadora utiliza as experiências cotidianas do aprendiz, sistematizadas e teorizadas, em uma relação dialógica e participativa. Conduz à transformação da realidade através da reflexão e da ação.

Nosso interesse, neste trabalho, foi envolver os profissionais que normalmente são responsáveis pelo treinamento materno bem como as próprias mães, de forma efetiva, no processo desde o início da construção do instrumento até sua utilização. 


\section{OBJETIVO}

Descrever o desenvolvimento de material didáticoinstrucional dirigido ao treinamento materno para a alta hospitalar do bebê prematuro, utilizando metodologia participativa.

\section{PERCURSO METODOLÓGICO}

Para o desenvolvimento de material didáticoinstrucional utilizamos a educação conscientizadora, também chamada problematizadora, fundamentada no referencial teórico de Paulo Freire, tendo por base a metodologia participativa. Essa educação, ao contrário da educação bancária, implica num constante ato de desvelamento da realidade, buscando a emersão das consciências, resultando na inserção crítica do homem na realidade. Tem como objetivos a transformação social, a troca de experiências, o questionamento, a individualização e a humanização ${ }^{(12-13)}$.

Na pesquisa participante, utilizamos o método que enfatiza a produção e comunicação de conhecimentos, propondo-se a: promover a produção coletiva de conhecimento, rompendo o monopólio do saber e da informação e permitindo que ambos se transformem em patrimônio dos grupos; promover a análise coletiva do ordenamento da informação e da utilização que dela se pode fazer; promover a análise crítica, utilizando a informação ordenada e classificada a fim de determinar as raízes e as causas dos problemas e as possibilidades de solução; estabelecer relações entre os problemas individuais e coletivos, funcionais e estruturais, como parte da busca de soluções coletivas aos problemas enfrentados $^{(14)}$.

Nessa seqüência metodológica há quatro fases: 1) montagem institucional e metodológica da pesquisa participante; 2) estudo preliminar e provisório da zona e da população em estudo; 3) análise crítica dos problemas considerados prioritários e que os pesquisadores desejam estudar e 4) a programação e execução de um plano de ação (incluindo ações educativas) para contribuir para o enfrentamento dos problemas colocados ${ }^{(14)}$.

Procuramos, inicialmente, verificar se havia interesse e disponibilidade dos sujeitos envolvidos no processo ensino-aprendizagem visando o treinamento materno para a alta do filho prematuro, através da aderência de educadores e educandos ao projeto.

Local do estudo

Berçário de prematuros, situado no $8^{\circ}$ andar do Hospital das Clínicas, Campus da Faculdade de Medicina de Ribeirão Preto da Universidade de São Paulo (HCFMRPUSP), hospital-escola público, de porte especial e de referência terciária para atendimento perinatal da regional de saúde de Ribeirão Preto, SP.

Sujeitos da pesquisa

Participaram do estudo duas enfermeiras (e1 e e2), sendo uma delas enfermeira-chefe, 53 anos de idade e 26 anos de enfermagem, 9 deles no campo do estudo, e a outra com 30 anos e com vínculo empregatício há 3 anos no campo do estudo; duas auxiliares de enfermagem (a1 e a2), uma com 53 anos de idade e 16 anos na enfermagem e a outra, 38 anos de idade e 6 anos de experiência na área e quatro mães de bebês prematuros (m1, m2, m3 e m4), internados no berçário, cujas características estão descritas na Tabela 1. As enfermeiras e auxiliares de enfermagem foram escolhidas por atuarem na unidade neonatal de cuidados intermediários há mais de três anos e apresentarem ampla experiência na orientação e preparo de mães de bebês pré-termo para a alta hospitalar de seus filhos.

Tabela 1 - Caracterização de mães, sujeitos da pesquisa

\begin{tabular}{|c|c|c|c|c|c|}
\hline № & Escolaridade & Gestação & Idade & \multicolumn{2}{|c|}{$\begin{array}{c}\text { Filho Prematuro } \\
\text { Idade Gestacional / Diagnóstico }\end{array}$} \\
\hline $\mathrm{m} 1$ & $\begin{array}{l}\text { ensino fundamental } \\
\text { incompleto }\end{array}$ & $\begin{array}{l}\text { multigesta } \\
\text { (3 abortos anteriores) }\end{array}$ & $35 \mathrm{a}$ & 34 semanas e 3 dias & $\begin{array}{l}\text { desconforto } \\
\text { respiratório precoce }\end{array}$ \\
\hline $\mathrm{m} 2$ & $\begin{array}{l}\text { ensino fundamental } \\
\text { completo }\end{array}$ & primigesta & $26 a$ & 32 semanas e 3 dias & $\begin{array}{l}\text { desconforto } \\
\text { respiratório }\end{array}$ \\
\hline $\mathrm{m} 3$ & $\begin{array}{l}\text { ensino fundamental } \\
\text { incompleto }\end{array}$ & $\begin{array}{l}\text { segundigesta } \\
\text { (primeiro prematuro - 12anos) }\end{array}$ & $23 a$ & 35 semanas e 1 dia & aspiração meconial \\
\hline $\mathrm{m} 4$ & 3o grau completo & primigesta & $25 \mathrm{a}$ & $\begin{array}{c}\text { gemelares }-31 \\
\text { semanas e } 5 \text { dias }\end{array}$ & $\begin{array}{l}\text { desconforto } \\
\text { respiratório precoce }\end{array}$ \\
\hline
\end{tabular}


Utilizamos os círculos de discussão para coleta de dados. É considerada uma técnica de abordagem qualitativa valorizada por conseguir trazer à tona as opiniões, relevâncias e valores dos sujeitos da pesquisa em relação a um determinado tema ${ }^{(15)}$.

Primeiro foram instalados dois pequenos círculos de discussão: um constituído por quatro participantes: duas enfermeiras (e1 e e2) e dois auxiliares de enfermagem (a1 e a2), e outro pelas quatro mães de prematuros ( $m 1$, m2, m3 e m4). Nesses dois grupos apresentamos a proposta de desenvolver material didático-instrucional para o preparo das mães para a alta hospitalar do filho prematuro e solicitamos que expressassem as suas expectativas frente à proposta. Estimulamos o levantamento dos problemas vivenciados na orientação para a alta hospitalar e dos temas relevantes para preparar a mãe para a alta hospitalar do bebê prematuro, na visão da enfermagem e das mães.

As atividades nos pequenos círculos de discussão foram organizadas tendo como foco os seguintes questionamentos:

1. Qual a relevância do material educativo nas atividades de educação em saúde para a alta hospitalar?

2. Quais temas e seus conteúdos deveriam ser trabalhados no material educativo?

3. Que tipo de material de ensino deveria ser utilizado?

As informações recolhidas foram devidamente organizadas e sistematizadas. Entretanto, enfatiza-se 0 aspecto de a pesquisa não se deter no recolhimento do que existe: o grupo deve participar dos dados encontrados para, através da conscientização, tentar a superação de problemas $^{(16)}$.

O produto concreto do processo vai do intercâmbio de experiências à objetivação, expresso através de temas geradores, os quais se referem a conteúdos específicos capazes de sintetizar o analisado. Os temas geradores são o conjunto de opiniões mais relevantes e significativas, em torno do problema apresentado. O conteúdo de cada tema gerador é especificado, determinando as unidades de trabalho ${ }^{(17)}$.

Após a realização dos dois círculos de discussão, houve um círculo de discussão maior, incluindo todas as participantes (e1, e2, a1, a2, m1, m2, m3 e m4). Os aspectos enfocados e identificados foram retomados para que elas se reapropriassem de suas expressões e sugestões. Nessa reunião conjunta, os participantes verificaram se houve correspondência entre seus anseios e críticas e discutiu-se sobre a forma do material educativo.

Foram realizados, ao todo, quatro encontros, no período de maio a outubro de 2001 , havendo a instalação dos "grupos de estudo ou círculos de discussão", com duração média de uma hora, nos quais o papel de animador foi desempenhado pela autora do presente estudo. As discussões foram gravadas na íntegra e, posteriormente, transcritas para a análise. Além disso, utilizamos o Diário de Campo para registros de manifestações não-verbais.

Utilizando as unidades de trabalho trazidas pelas participantes, as pesquisadoras elaboraram os conteúdos, tendo por base a literatura. A revisão desses conteúdos foi feita por quatro enfermeiras, uma professora de enfermagem e três enfermeiras assistenciais, sendo duas de unidade neonatal e outra do banco de leite humano.

A retroalimentação, no final dessa fase, foi a devolução do material confeccionado ao grupo. É, precisamente, nessa fase que reside a característica desse tipo de pesquisa, voltado para a ação, no sentido de se tentar fazer alguma coisa além da mera constatação de problemas ${ }^{(16)}$. Uma cópia do material piloto, de manufatura simples e artesanal, com os temas desenvolvidos e suas respectivas ilustrações, foi entregue, em casa, para cada participante a fim de que pudessem manuseá-lo e ler tranqüilamente.

Enfermeiras e auxiliares de enfermagem foram instruídas sobre os tópicos para avaliar, validando o conteúdo e aparência do material didático-instrucional. Para tal, elaboramos um instrumento, tendo por base outro, já proposto ${ }^{(18)}$, para avaliação da dificuldade e da conveniência de materiais educativos, denominado Suitability Assessment of Materials (SAM).

Para as mães, solicitamos que destacassem os termos técnicos que porventura não tinham sido entendidos e, após uma semana de prazo, elas foram procuradas para se expressarem a respeito da cartilha.

Procedimentos

Os procedimentos encontram-se sintetizados na Tabela 2. 
Tabela 2 - Fases metodológicas da construção do material didático-instrucional dirigido à orientação materna para a alta hospitalar do filho prematuro, através da metodologia participativa.

\begin{tabular}{|c|c|c|c|}
\hline Fases $(1999-2001)$ & Data & Duração & Atividades desenvolvidas \\
\hline Montagem institucional & & & Definição do objetivo e da metodologia. \\
\hline $\begin{array}{c}\text { e metodológica da } \\
\text { pesquisa }\end{array}$ & $\begin{array}{l}\text { nove } \\
\text { dez/00 } \\
\text { mar/01 } \\
\text { dez/99 }\end{array}$ & 2 anos & $\begin{array}{l}\text { Discussão do projeto com as enfermeiras e banca } \\
\text { examinadora. } \\
\text { Elaboração do cronograma de atividades. } \\
\text { Insercão e exploracão de campo }\end{array}$ \\
\hline $\begin{array}{l}\text { provisório da zona e da } \\
\text { população em estudo }\end{array}$ & abr/01 & & $\begin{array}{l}\text { Contato com os participantes para verificar aderência } \\
\text { ao projeto. } \\
\text { Escolha dos participantes: } \\
\begin{aligned}- & 2 \text { enfermeiras; } \\
\text { - } \quad 2 \text { auxiliares de enfermagem; } & \text { - } 4 \text { mães de prematuros. }\end{aligned}\end{array}$ \\
\hline
\end{tabular}

Análise crítica dos abr/01

problemas

considerados

prioritários

Mães: 03/05/01 45 minutos
Enfermagem: 40 minutos
09/05/01
mai/01

$14 / 5 / 01 \quad 50$ minutos

jun e jul/01

ago e set/01

set/01

set/01

out e nov/01

Procedimentos éticos

O projeto foi submetido ao Comitê de Ética do HCFMRP-USP, sendo aprovado. As participantes assinaram o Termo de Consentimento Livre e Esclarecido.

\section{RESULTADOS}

Este item versa sobre o desenvolvimento do material educativo para o treinamento de mães visando a alta hospitalar do filho prematuro, construído através da participação das enfermeiras, auxiliares de enfermagem e mães de prematuros. Para fins didáticos, dividiremos a apresentação em duas fases:

- Círculos de discussão

- Validação da cartilha educativa.
Formação de círculos de discussão:

1) com as 4 mães de prematuros;

2) com as 2 enfermeiras e 2 auxiliares de enfermagem.

Discussão nos círculos sobre:

- relevância do material educativo;

- temas que deveriam ser trabalhados;

- tipo de material de ensino que deveria ser utilizado.

Formação do círculo de discussão com todos os participantes.

Comunicação dos resultados dos círculos pequenos e discussão no círculo grande de como seria a apresentação e a forma do material educativo.

Elaboração do conteúdo de cada tema proposto nos pequenos círculos, tendo por base a literatura.

Revisão dos conteúdos por quatro profissionais.

Confecção do material piloto.

Entrega em domicílio do material para validação pelas participantes.

Leitura das validações das participantes e das sugestões dos profissionais e correção do material.

Círculos de discussão: subsídios para a elaboração do material didático-instrucional

Diante da proposta de desenvolvimento de um material educativo, as mães e profissionais de enfermagem foram incentivadas a se expressarem sobre a relevância desse nas atividades de Educação em Saúde, dirigidas ao preparo materno para a alta hospitalar do bebê prematuro. Para a enfermagem, o material direciona as orientações a serem ministradas às mães, conforme demonstram as falas:

...se tiver o material adequado, a gente direciona o treinamento. porque cada enfermeira, auxiliar, tem um enfoque melhor para cada situação, mas com um material educativo adequado, a gente está direcionando a atividade educativa de uma maneira só. Um material ia dar uma seqüência.(...) É muito vasto, porque nessa parte tem muita carência (recursos). Cada um fala do seu jeito, orienta do seu jeito, orienta uma coisa e não fala de outra. dá prioridade do seu jeito, nas coisas que quer (e1). 
Eu acho que um material educativo estaria direcionando o treinamento para a alta, nas necessidades das mães, aumentando o sucesso da alta (...) ...são muitos detalhes, às vezes, como a nossa demanda é muito grande, a gente acaba deixando coisas pra trás que não é importante pra gente, mas que é de extrema importância pra mãe. Eu acho que ter um instrumento escrito que a gente lesse e já lembraria do que tem que orientar e que ajudasse a mãe (e2).

É importante porque um material ia ajudar a gente a conversar com essas mães para elas ficarem mais seguras na hora da alta (a2).

A preocupação materna e da equipe de enfermagem na falta de padronização das orientações também aparece, em um estudo, quando as mães expressam o descontentamento devido à ocorrência de informações contraditórias, que podem ser diminuídas se os profissionais de saúde trabalharem para dar maior consistência às informações e recomendações ${ }^{(9)}$.

Foi destacado, ainda, que um material didáticoinstrucional escrito modifica a prática de Educação em Saúde e auxilia a mãe na memorização dos conteúdos a serem aprendidos:

A gente tem que mostrar um negócio legalzinho, fazer uma coisa gostozinha mesmo. Então, eu acho que aí é que entra o material. Mudar rotina mesmo (...) porque você explica, mas ela (mãe) não fixa. A maneira como a gente está explicando não está dando pra ela fixar (...) o linguajar do médico não dá pra atingir, não dá pra entender; eu não entenderia. Eles falam, elas (mães) não entendem e chegam em casa e fantasiam (e1).

Com o material eu acho que a orientação fica diferente (...) A mãe tá tão ansiosa pra levar o bebê pra casa que ela acaba não assimilando (e2).

(...) e o jeito que vai ser orientada é muito importante (...) Pra mim, se a informação fosse falada, não resolveria; eu não vou guardar detalhe por detalhe na cabeça. Material te ensina a saber a hora que o neném tá bem ou não (m1).

(...) porque se só falar mesmo, é tanta coisa pra aprender que não dá pra guardar tudo... (m2).

São encontradas poucas pesquisas sobre a aprendizagem ou as necessidades de aprendizagem das mães de bebês prematuros ${ }^{(9)}$.

Quanto aos temas que o material educativo deveria abordar, as mães e profissionais de enfermagem foram incentivadas a discorrer sobre o que achavam importante aprender e ensinar, respectivamente.

Durante os círculos de discussão, as participantes identificaram cinco temas geradores: cuidados especiais, alimentação, higiene, cuidados diários e relacionamento familiar.
Especificaram, a partir dos temas geradores, 27 assuntos de interesse para o processo ensinoaprendizagem, denominados unidades de trabalho. Algumas delas mencionaram o mesmo assunto por mais de uma vez, como aleitamento, banho e relação mãe-filho, o que denota a sua importância na capacitação materna para o cuidado do prematuro no domicílio.

Tabela 3 - Temáticas de interesse

\begin{tabular}{|c|c|c|}
\hline Temas Geradores & Unidades de Trabalho & $\begin{array}{l}\text { Número de vezes } \\
\text { que as unidades de } \\
\text { trabalho foram } \\
\text { citadas nos grupos }\end{array}$ \\
\hline Cuidados & Engasgo & 6 \\
\hline \multirow[t]{6}{*}{ especiais } & Medicação & 6 \\
\hline & Situações de risco & 5 \\
\hline & Regurgitação/vômito & 3 \\
\hline & Infecções & 3 \\
\hline & Seguimento & 3 \\
\hline & $\begin{array}{c}\text { Lista de serviços de } \\
\text { apoio }\end{array}$ & 2 \\
\hline \multirow[t]{7}{*}{ Alimentação } & Aleitamento & 10 \\
\hline & $\begin{array}{c}\text { Produção e manutenção } \\
\text { da lactação }\end{array}$ & 9 \\
\hline & Sucção & 5 \\
\hline & Uso de sonda gástrica & 4 \\
\hline & Uso do copinho & 4 \\
\hline & Relactação & 3 \\
\hline & Armazenamento do leite & 2 \\
\hline \multirow[t]{5}{*}{ Higiene } & Banho & 9 \\
\hline & Troca de fralda & 4 \\
\hline & Conhecimentos básicos & 3 \\
\hline & Limpeza do períneo & 2 \\
\hline & Roupa & 2 \\
\hline \multirow[t]{5}{*}{ Cuidados diários } & Choro & 6 \\
\hline & Sono & 4 \\
\hline & Frio & 4 \\
\hline & Banho/sol & 2 \\
\hline & Transporte de bebês & 2 \\
\hline \multirow{3}{*}{$\begin{array}{l}\text { Relacionamento } \\
\text { familiar }\end{array}$} & Relação mãe-filho & 7 \\
\hline & Apoio em casa & 3 \\
\hline & Visitas em casa & 2 \\
\hline
\end{tabular}

Cada tema gerador e respectivas unidades de trabalho foram explorados no material didático-instrucional, como sendo relevantes ao preparo da mãe para a alta do bebê prematuro, sendo criados os conteúdos.

Alguns dos assuntos colocados pelas participantes foram citados, em outro estudo, alimentação, cólicas, infecção, respiração ruidosa e reconhecimento de risco ${ }^{(19)}$.

Todas as participantes verbalizaram interesse em ter um material escrito, sendo sugerido um livreto, revistinha e cartilha com texto sobre os cuidados e figuras:

...tipo uma cartilhinha que tivesse figura e escrito e que ela guarda com ela (e1).

Acho que com um livrinho, a mãe vai ter aquela curiosidade pra ler. Eu acho que deveria ser um instrumento escrito (a2). 
Tipo uma revistinha que a gente possa ver e ler, com figura e escritinho (...) tipo um livrinho. Com umas fotos, explicando e a gente lendo (m1).

...que você vai vendo e lendo (m3).

É muita coisa pra guardar então eu acho melhor escrever, fazer um livro (m4).

A expectativa das participantes, em especial das mães, é que a cartilha educativa permaneça com a mãe para ser consultada no domicílio, se tiver dúvidas acerca dos cuidados com o filho prematuro:

É difícil, né? Porque na hora não aparecem as dúvidas, na hora que a gente tiver em casa, tinha que ter um negócio pra consultar, pra ver (m3).

Na hora que o médico, a enfermeira tá lá, a dúvida não vem, dá um branco, depois vem a dúvida (m2).

É tanta coisa que a gente vai ter que aprender pra cuidar do neném prematuro que a gente não vai guardar tudo na cabeça. Aí se tiver uma coisa pra levar pra casa pra quando tiver dúvida olhar, ir lendo aqui (m1).

(...) que ela (mãe) pudesse levar pra casa, um material dela. Ela vai ter dúvida, e consultar alguma coisa nesse material e com isso ver outras coisas (e1).

Em um estudo ${ }^{(9)}$, já citado, também é explicitado pelas mães a necessidade de material impresso, sobre os cuidados com os bebês prematuros, disponível na forma de brochuras que possam ser levadas do hospital para casa. Para esse público, o acesso às informações sobre desenvolvimento, cuidados, alimentação e riscos do prematuro deveria ser melhorada. Muitos livros e artigos são escritos para enfermeiras e médicos, mas existe muito pouco para o público materno ${ }^{(9)}$.

Nos círculos de discussão também foi sugerida a inclusão de fotos ou figuras coloridas para a ilustração do material educativo.

(...) foto ou mostrar figura, dá na mesma (m1).

(...) tanto faz figura ou foto (m4).

Então teria que ter coisas ilustrando mesmo, né? Fazendo ela (mãe) lembrar... e também escrito (e1).

(...) figuras são muito importantes, mas tem que ter escritos, como uma revistinha (a1).

Pra ficar curiosa pra ler, tem que ter figuras coloridas (a2).

A ilustração refere-se ao desenho de fundo, à figura que dá vida ao material ${ }^{(18,20)}$.

A imagem, fator decisivo na atitude de ler ou não a instrução, deve ser amigável, chamar a atenção do público-alvo e retratar claramente o propósito do material. Desenhos de linhas simples podem promover realismo, sem incluir detalhes indesejados. As fotografias incluem, freqüentemente, detalhes não desejados e desnecessários, como fundo de quarto, bordas elaboradas, cor desnecessária e podem distrair o leitor. As ilustrações devem apresentar mensagens fundamentais visualmente, sem nenhum tipo de distração ${ }^{(18)}$.

A cor é um importante fator na comunicação visual gráfica. Os estudos sobre a utilização das cores e seu efeito sobre as pessoas têm sido cada vez mais aprofundados, em virtude do seu poder em despertar a atenção do espectador ${ }^{(18,20)}$.

Para o material educativo, produzido nesta investigação, as figuras foram desenhadas por uma criança de 10 anos, em preto e branco, posteriormente coloridas por um técnico em tratamento de imagem, com a ajuda do programa de computação gráfica Corel Draw.

Com relação ao texto do material educativo, as participantes optaram pela sua disposição no formato pergunta/resposta e apresentação do conteúdo de forma objetiva e de fácil compreensão.

(...) tipo perguntinha, ter escrita fácil e clara (e1).

(...) perguntinha e resposta, né? Com pergunta bem objetiva (m1).

É bem interessante, pergunta e resposta (m4).

Assim, os textos, com os conteúdos educativos da cartilha, são apresentados na forma de perguntas e respostas. Esse formato, ao discutir problemas e suas soluções, fazer escolhas e demonstrar, aumenta a retenção do conteúdo pelo leitor. Recomenda-se, ainda, o uso de cabeçalhos ou legendas de tópicos para informar ao leitor, sucintamente, o assunto em questão ${ }^{(18)}$.

$\mathrm{Na}$ cartilha produzida, a pergunta/resposta vem acompanhada de ilustração. Além das figuras, o material foi paginado com dispositivos visuais editados no Corel Draw, conforme recomendação da literatura especializada. As ilustrações devem estar na mesma página adjacente ao texto relacionado. Dispositivos visuais (caixas, setas) dirigirem a atenção para pontos específicos ou conteúdos fundamentais ${ }^{(18)}$. O texto deve ser breve, direto, com linguagem simples e especialmente compreensível à clientela a que se destina ${ }^{(18,20)}$.

Frases longas reduzem a velocidade no processo de leitura e geralmente geram compreensão mais difícil. Palavras comuns devem ser usadas quase o tempo todo. Palavras técnicas e conceitos devem ser explicados através de exemplos ${ }^{(18)}$. 
Os textos foram escritos utilizando-se um estilo de letras simples e fáceis de serem lidas. O tamanho da letra é proporcional à distância a que o material será lido, ou seja, em média 30 centímetros de distância e letras de tamanho 14.

Quando muitos tipos de fontes e tamanhos diferentes (seis ou mais) são usados em uma página podem confundir o leitor e deixar o foco incerto, sendo sugerido, para pontos fundamentais, negrito e tipo de fonte, tamanho e cores diferentes ${ }^{(18)}$.

Foram utilizados dois tipos de fontes: "Hobo BT", por ser uma letra mais elaborada, sem deixar de ser de fácil compreensão, foi escolhida para os títulos e a "Benguiat BK BT", para os conteúdos maiores, por ser uma fonte simples e clara. Essas fontes tiveram cores diferentes de acordo com o destaque que se pretendia dar ao texto, azul para perguntas e preto para as respostas.

Validação da cartilha educativa

Com base nas expectativas, sugestões e decisões dos participantes dos círculos de discussão, construímos a cartilha educativa. Os conteúdos técnicos, pertinentes aos temas abordados na cartilha, foram elaborados fundamentados na literatura e experiência profissional da pesquisadora. Posteriormente, os conteúdos foram revisados por dois profissionais da saúde.

Após uma semana de prazo para leitura do material, visando validar a aparência e conteúdo do material educativo, as participantes foram procuradas para devolução das anotações e sugestões feitas e foram estimuladas a verbalizar sobre o material educativo.

Sobre o instrumento entregue à equipe de enfermagem, houve concordância em todos os atributos apresentados.

Há a preocupação de uma das enfermeiras participantes, relacionando o tamanho da cartilha à escassez de recursos financeiros da instituição; trata-se da dificuldade de distribuição, posterior, à clientela a que essa se destina. Ela escreveu no final do instrumento:

Achei a cartilha muito rica, com muitas páginas, mas durante a leitura concluí que não dá para haver cortes, pois um assunto dá seqüência ao outro. Sugiro que seja utilizada como empréstimo à família, durante a fase de internação do bebê (e1).

O empréstimo não satisfaz às mães, que desejam ter um material seu, para consulta, quando necessário.

A sugestão dada por duas mães é que a palavra "enfatizado", que aparecia no início da cartilha, na justificativa, deveria ser substituída por outra de fácil entendimento. Sendo trocada por "destacado".

As mães apresentaram os seguintes comentários:

Deu pra entender bem. Está bem explicado. O que tem que fazer pra cuidar bem do bebê tem na cartilha. Os desenhos são bem demonstrativos. Ajudam bem. É bem interessante, ficou ótimo, porque a gente começa a ler e quer ver o final. As mães vão gostar muito. Porque eu, cuidando dela (filha prematura) em casa, é bem isso mesmo que a gente quer saber (m3).

Está organizadinha, interessante. Cabe tudo que precisa. Se diminuir, tira coisa importante. Porque tem tudo que precisa saber. Se tirar coisa, ela não vai ficar tão completa igual tá. Tem tudo (...) tudo ótimo, bem objetivo. Mesmo sendo grande (cartilha), cada item é bem resumido, aí fica gostoso ler, li rápido. É bem do jeito que precisa mesmo (m4).

A "m2" não participou da fase de validação da cartilha, pois, após a alta do filho, foi passar uma temporada na companhia da mãe, residente em outro município, não deixando o endereço.

O material, intitulado "Cuidados com o bebê prematuro: cartilha educativa para orientação materna", contém 48 páginas e apresenta-se dividido em justificativa, objetivo, breve conceituação sobre o bebê prematuro, 29 perguntas e respostas sobre relacionamento familiar (3), alimentação (9), higiene (3), cuidados diários (9) e especiais (5), lista de telefones úteis, anotações e referências bibliográficas.

Sua arte final e diagramação foram realizadas através de assessoria técnica do setor de audiovisual da Escola de Enfermagem de Ribeirão Preto da Universidade de São Paulo.

Após as últimas modificações, proporcionadas pelos participantes através da validação da assessoria técnica, o material foi impresso em gráfica e reproduzido.

A cartilha foi confeccionada em papel cuchê, específico para impressão de figuras pela qualidade fotográfica das cores. $O$ tamanho da página é de meia folha A4 (150x210mm) e em formato de configuração "paisagem", considerado adequado para o objetivo a que se propõe.

A última fase da pesquisa participativa, a programação e execução de um plano de ação, incluindo ações educativas para contribuir no enfrentamento dos problemas colocados, não fizeram parte de nosso objetivo, no presente estudo; será realizada em estudos posteriores. 


\section{CONSIDERAÇÕES FINAIS}

Baseadas nas teorias de Paulo Freire, em que todos os seres vivos aprendem por meio da interação com o ambiente, escolhemos a metodologia participativa, na qual mães, enfermeiras e auxiliares de enfermagem atuaram efetivamente no processo de desenvolvimento de uma cartilha educativa sobre os cuidados com o bebê prematuro.

Essa metodologia mostrou-se adequada, de fácil compreensão e condução para o alcance do objetivo proposto, abrindo novo e estimulante caminho para as atividades de Educação em Saúde.

A experiência demonstrou que as mães e a equipe de enfermagem dinamizaram as atividades de Educação em Saúde, sentindo-se estimuladas e empenhadas na construção conjunta do material didático-instrucional. Houve consenso e segurança ao optarem por uma cartilha educativa, no formato pergunta/resposta com ilustrações elucidativas.

Mais do que oferecer uma coletânea de perguntas e respostas, apresentamos referenciais que auxiliam o desenvolvimento das potencialidades das mães e instigam a equipe de enfermagem a trabalhar de forma dinâmica com um aliado, o material educativo. No treinamento de mães de prematuros, esperamos que a cartilha seja uma catalisadora que estimule o interesse da equipe para explorar os materiais educativos. Esse material instrucional foi desenvolvido para desafiar mães e equipe a participar, a trabalhar numa construção conjunta.

Os assuntos trabalhados na cartilha são voltados para as práticas cotidianas, de cuidados simplificados. Contrastam com a literatura levantada, que traz tópicos pedagógicos mais rígidos e técnicos.

Na literatura consultada sobre o preparo da mãe para a alta hospitalar do filho prematuro, não encontramos a participação entre os recursos de aprendizagem utilizados. As mães, nesses estudos, expressaram a falta

\section{REFERÊNCIAS BIBLIOGRÁFICAS}

1. Ministério da Saúde (BR). Educação para a participação em saúde. Diretrizes gerais. Brasília (DF): Ministério da Saúde; 1992.

2. Medeiros SM. Formas de conhecimento em saúde: confrontos e viabilização em uma prática de educação em saúde. [Dissertação]. João Pessoa (PB): Centro de Educação/ UFPb; 1995. de alguém para conversar sobre o seu bebê prematuro, além da dificuldade em entender a terminologia médica, quando recebem orientação dos profissionais.

No nosso estudo, a discussão, a troca de experiências, a tomada de decisão e a parceria foram prérequisitos para o desenvolvimento do material educativo, já que utilizamos a pesquisa participante. As mães não apresentaram dificuldades com a terminologia médica, pois o entendimento e a elucidação dos termos foi se dando no processo, em linguagem comum aos participantes.

Consideramos, também, que este estudo pode contribuir com o preparo técnico-intelectual dos profissionais de saúde com vistas à assistência integral em berçário, suscitando, nesses, o desejo de ousar, de criar, partindo do pressuposto de que a participação possibilita a aquisição de conhecimento e a troca de experiências sobre os cuidados com o bebê prematuro entre mães e equipe de enfermagem, e que um instrumento direciona as orientações de Educação em Saúde, tornando-as mais interessantes e estimulantes, para a equipe e para as mães.

Há necessidade de avaliações posteriores do impacto no processo ensino-aprendizagem da utilização da forma participativa nas atividades de Educação em Saúde, na perspectiva da equipe de enfermagem e clientela.

Acreditando que nenhum conhecimento é estático, poderíamos propor revisões periódicas da cartilha educativa desenvolvida, mas isso não é suficiente, pois estaríamos negando a premissa da forma participativa de se trabalhar em grupos. A cartilha está adequada ao grupo que a construiu. A participação desse grupo gerou esse produto com esses assuntos; outros grupos virão e poderão gerar outros produtos ou meios. Mas se desejarem utilizar esse produto existente, as adequações na construção participativa de conhecimento pela clientela se darão no processo.

3. Ministério da Saúde (BR). Secretaria Nacional de Assistência à Saúde. Departamento de Programas de Saúde. Coordenação de Educação para a Saúde. Educação para a saúde; plano estratégico. Brasília; 1992.

4. Scochi CGS. A humanização da assistência hospitalar ao bebê prematuro: bases teóricas para o cuidado de enfermagem. [Tese]. Ribeirão Preto (SP): Escola de Enfermagem de Ribeirão Preto/USP; 2000.

5. Edwards M. Discharge planning. In: Avery GB, Fletcher MA, MacDonald MG. Neonatology: pathophysiology and management of newborn. Philadelphia: J.B. Lippincott; 1999. p.3-7. 
6. Wiggins JB. Family-centered nursing care in the intensive care nursery. In: Avery GB, Fletcher MA, MacDonald MG. Neonatology: pathophysiology and management of newborn. Philadelphia: J.B. Lippincott; 1999. p.68-75.

7. Madeira LM. Alta hospitalar da criança: implicações para a enfermagem. Rev Bras Crescimento Des Humano 1994; 4(2):5-11.

8. Baker K, Kuhlmann T, Magliaro BL. Discharge teaching for parent of newborns with special needs. Nurs Clin North Am 1989; 24(3):655-64.

9. Brown Y. Learning projects of mothers of preterm and low birth weight infants. Nur Papers/Perspect Nurs 1986; 3:5-16. 10. Fonseca LMM, Scochi CGS. Inovando a assistência de enfermagem ao binômio mãe-filho em alojamento conjunto neonatal através da criação de um jogo educativo. Rev Latinoam Enfermagem 2000 setembro-outubro; 8(5):106-8.

11. Fonseca LMM, Scochi CGS, Bis CEF, Serra SOA. Utilizando a criatividade na educação em saúde em alojamento conjunto neonatal: opinião de puérperas sobre o uso de um jogo educativo. Rev Bras Enfermagem 2000; 53(2):301-10.

12. Freire P. Pedagogia do oprimido. Rio de Janeiro (RJ): Paz e Terra; 1999.

13. Freire P. Educação como prática de liberdade. Rio de Janeiro (RJ): Paz e Terra; 1983.

14. Le Boterf G. Pesquisa participante: propostas e reflexões metodológicas. In: Brandão CR, organizador. Repensando a pesquisa participante. São Paulo (SP): Brasiliense; 1999. p.51-81.

15. Santos JBG. Avaliação emancipatória: uma alternativa para a facilitação da aprendizagem na disciplina enfermagem em centro cirúrgico. [Dissertação]. Ribeirão Preto (SP): Escola de Enfermagem de Ribeirão Preto/USP; 1996.

16. Valle ERM do. A pesquisa participante como metodologia de pesquisa em enfermagem. Enfoque 1988; 16(1):20-3.

17. Martinic S, Sainz HI. Investigación participativa y cultura popular: una experiencia en curso. Cadernos CEDES 1987; 12:15-31.

18. Doak CC, Doak LG, Root JH. Teaching patients with low literacy skills. Philadelphia: J.B. Lippincott; 1996.

19. Miles MS, Holditch-Davis D. Parenting the prematurely born child: pathways of influence. Semin Perinatol 1997; 21(3):254-66.

20. Ferreira OMC, Silva PD Jr. Recursos audiovisuais no ensino-aprendizagem. São Paulo (SP): Pedagógica \& Universitária; 1986. 